\title{
Ferroelectric-antiferroelectric mixed systems. Equation of state, thermodynamic functions
}

\author{
N.A.Korynevskii ${ }^{1,2}$, V.B.Solovyan ${ }^{1}$ \\ ${ }^{1}$ Institute for Condensed Matter Physics \\ of the National Academy of Sciences of Ukraine, \\ 1 Svientsitskii Str., Lviv 79011, Ukraine, \\ 2 Institute of Physics, University of Szczecin, \\ 15 Wielkopolska Str., 70451 Szczecin, Poland
}

Received August 19, 2005

\begin{abstract}
The problem of equation of state for ferroelectric-antiferroelectric mixed systems in the whole region of a concentration change $(0 \leqslant \boldsymbol{n} \leqslant 1)$ is discussed. The main peculiarity of the presented model turns out to be the possibility for the site dipole momentum to be oriented ferroelectrically in $\boldsymbol{z}$-direction and antiferroelectrically in $\boldsymbol{x}$-direction. Such a situation takes place in mixed compounds of KDP type. The different phases (ferro-, antiferro-, paraelectric, dipole glass and some combinations of them) have been found and analyzed.
\end{abstract}

Key words: ferroelectrics and antiferroelectrics, mixed systems, equation of state

PACS: $75.10 . H k, 77.22 . C h, 77.84 . F$

The present paper is a continuation of our recent investigations of ferroelectric-antiferroelectric mixed systems with hydrogen bonds [1-3]. There is an abundant experimental material concerning phase diagrams and the behaviour of thermodynamic functions for this mixed crystals [4-8]. The phase diagrams demonstrate the coexistence of pure and mixed ferro-, antiferro-, paraelectric, dipole glass phases in a wide region of temperatures and concentrations. A theoretical description of such systems is in its initial stage so far. The main approach is based on the statistic replica method for calculating the thermodynamic functions for a mixed system with non-equilibrium distribution of differently occupied sites, similar to the ones exploited in mixed ferromagnetic system investigations [9].

It is well known that short range interparticle interactions play an important role in ferroelectrics (especially in hydrogen bonded ones). So, in order to adequately describe the ferroelectricantiferroelectric mixed systems we should take into account both the short and long range interactions. An effective method was proposed in [2], where the model Hamiltonian includes two subsystems of particles with dipole momenta perpendicular to each other, with short and long range interaction between them and which depend on the probability of occupying each lattice site. In the second order of replica expansion for $-\beta H\left(\beta=(k T)^{-1}, k\right.$ is the Boltzmann constant and $T$ is the absolute temperature) the free energy of the system investigated has been obtained. The equations for ferroelectric $P=\left\langle\overline{S^{z}}\right\rangle$, antiferroelectric $\xi=\left\langle\overline{S^{x}}\right\rangle$ order parameters and dipole glass $g_{z}=\left\langle\overline{S_{m i}^{z} S_{m^{\prime} i}^{z}}\right\rangle, g_{x}=\left\langle\overline{S_{m i}^{x} S_{m^{\prime} i}^{x}}\right\rangle$ parameters were found. Here $\langle\cdots\rangle$ denotes thermal averaging for a given distribution of $z$ - and $x$-oriented dipole momenta of particles whereas a bar denotes a stochastic averaging over different distributions; $m, m^{\prime}$ denotes the nearest neighbours of particles in $i$-th size. The obtained phase diagram (the temperature of the corresponding order parameter appearing versus concentration) shows a possibility of different phases occurring: ferro-, antiferro-, paraelectric, dipole glass and some combinations of them.

The purpose of the present paper is to perform a continual study of ferroelectric-antiferroelectric mixed system taking into account the interaction processes between both subsystems, i.e. ferroelectric and antiferroelectric ones. In this approach and using the replica method $[9,10]$ we will obtain a phase diagram, the equation of state and expressions for base thermodynamic functions 
of the system investigated. We will compare our results to the known experimental data concerning mixed Rubidium Ammonium Dihydrogen Arsenate $\mathrm{Rb}_{n}\left(\mathrm{NH}_{4}\right)_{1-n} \mathrm{H}_{2} \mathrm{AsO}_{4}$ (RADA).

Taking the two-particle cluster approximation (see [11]) for short range interaction among particles and the self-consistent field approximation with the accuracy up to the second order of replica expansion for long range one we have for $-\beta H$ the expression which contains the terms describing the correlation between ferroelectric and antiferroelectric subsystems

$$
\begin{aligned}
-\beta H= & \sum_{i=1}^{N}\left\{A_{1}^{(i)} S_{1 i}^{z} S_{2 i}^{z}+B_{1}^{(i)}\left(S_{1 i}^{z}+S_{2 i}^{z}\right)+A_{2}^{(i)} S_{1 i}^{x} S_{2 i}^{x}+B_{2}^{(i)}\left(S_{1 i}^{x}-S_{2 i}^{x}\right)-J_{1} \frac{V_{f}}{V} P^{2}\right. \\
& -\left(\tanh \beta V-J_{1}\right) \frac{U_{a f}}{V} \xi^{2}-\frac{J_{2}}{2}\left[-2+\left(g_{z}-\frac{U}{V} g_{x}\right)^{2}+\right. \\
& +\left(\frac{V_{f}+V_{a f}}{V}+\frac{V_{f}-V_{a f}}{V} g_{z}\right)^{2}+\left(\frac{U_{f}+U_{a f}}{V}+\frac{U_{f}-U_{a f}}{V} g_{x}\right)^{2} \\
& \left.\left.+24\left(\frac{V_{f}}{V} P^{2}-\frac{U_{a f}}{V} \xi^{2}\right)^{2}\right]\right\} .
\end{aligned}
$$

Here

$$
\begin{aligned}
& J_{1}=\sum_{t=1}^{\infty}(-1)^{t} 2 \ln \left(1-n+n \mathrm{e}^{-2 \beta V t}\right), \\
& J_{2}=\sum_{t=1}^{\infty}(-1)^{t} 4 t \ln \left(1-n+n \mathrm{e}^{-2 \beta V t}\right)
\end{aligned}
$$

are the functions which describe a relative contribution of each phase into the general properties of a mixed system $\left(J_{1}\right)$ and a correlation between those phases $\left(J_{2}\right), n$ is a concentration of ferroelectrically ordered particles.

$$
\begin{aligned}
& V_{f}=\frac{1}{2} \sum_{j=1}^{N}\left(V_{i j}^{11}+V_{i j}^{12}\right), \quad U_{f}=\frac{1}{2} \sum_{j=1}^{N}\left(U_{i j}^{11}+U_{i j}^{12}\right), \\
& V_{a f}=\frac{1}{2} \sum_{j=1}^{N}\left(V_{i j}^{11}-V_{i j}^{12}\right),
\end{aligned}
$$

and $V$ and $U$ are the energies of intrasite interactions between particles for both subsystems

$$
\begin{aligned}
A_{1}^{(i)} & =J_{1}+J_{2}\left[\frac{V_{f}^{2}-V_{a f}^{2}}{V^{2}}+\left(1+\left(\frac{V_{f}-V_{a f}}{V}\right)^{2}\right) g_{z}-\frac{U}{V} g_{x}\right], \\
B_{1}^{(i)} & =J_{1} \frac{V_{f}}{V} P+4 J_{2}\left[\left(\frac{V_{f}}{V}\right)^{2} P^{3}-\frac{V_{f}}{V} \frac{U_{a f}}{V} P \xi^{2}\right], \\
A_{2}^{(i)} & =\left(\tanh \beta V-J_{1}\right) \frac{U}{V}+J_{2}\left[\frac{U_{f}^{2}-U_{a f}^{2}}{V^{2}}+\left(\left(\frac{U}{V}\right)^{2}+\left(\frac{U_{f}-U_{a f}}{V}\right)^{2}\right) g_{x}-\frac{U}{V} g_{z}\right], \\
B_{2}^{(i)} & =\left(\tanh \beta V-J_{1}\right) \frac{U_{a f}}{V} \xi+4 J_{2}\left[\left(\frac{U_{a f}}{V}\right)^{2} \xi^{3}-\frac{V_{f}}{V} \frac{U_{a f}}{V} P^{2} \xi\right] .
\end{aligned}
$$

Performing the trace operation in the formula for free energy

$$
F=-\frac{1}{\beta} \ln T r \mathrm{e}^{-\beta H}
$$


over cluster states of spin operators $S_{f i}^{z}, S_{f i}^{x}$ and minimizing the obtained expression with respect to all order parameters $P, \xi, g_{z}, g_{x}$ the set of equations of state can be written

$$
\begin{aligned}
& P=Z^{-1} \mathrm{e}^{A_{1}} \sinh 2 B_{1}\left(\mathrm{e}^{A_{2}}+\mathrm{e}^{-A_{2}} \cosh 2 B_{2}\right), \\
& \xi=Z^{-1} \mathrm{e}^{-A_{2}} \sinh 2 B_{2}\left(\mathrm{e}^{-A_{1}}+e^{A_{1}} \cosh 2 B_{1}\right), \\
& g_{z}=-Z^{-1}\left(\mathrm{e}^{-A_{1}}-\mathrm{e}^{A_{1}} \cosh 2 B_{1}\right)\left(\mathrm{e}^{A_{2}}+\mathrm{e}^{-A_{2}} \cosh 2 B_{2}\right), \\
& g_{x}=Z^{-1}\left(\mathrm{e}^{-A_{1}}+\mathrm{e}^{A_{1}} \cosh 2 B_{1}\right)\left(\mathrm{e}^{A_{2}}-\mathrm{e}^{-A_{2}} \cosh 2 B_{2}\right), \\
& Z=\left(\mathrm{e}^{-A_{1}}+\mathrm{e}^{A_{1}} \cosh 2 B_{1}\right)\left(\mathrm{e}^{A_{2}}+\mathrm{e}^{-A_{2}} \cosh 2 B_{2}\right) .
\end{aligned}
$$

To solve the set (6) in general form is a rather complicated problem. But the phase diagram of the system investigated can be obtained as a line dividing different possible phases in coordinates: concentration - temperature. Such diagram (approximated to a real RADA system) is presented in figure 1. One can observe the existence of paraelectric $(P)$, ferroelectric $(F)$, antiferroelectric $(A F)$, dipole glass $(G)$ phases and some combinations thereof: ferroelectric-dipole glass $(F-G)$, antiferroelectric-dipole glass $(A F-G)$. It should be noted that the occurrence of dipole glass phase is fixed as a point of bifurcation of the number of roots of the system (6) for correlation functions of the nearest neighbours $g_{z}$ and $g_{x}$. So, at low temperatures a uniform kind of short range correlation changes into the nonuniform one described by a set of functions $g_{z}, g_{x}$.

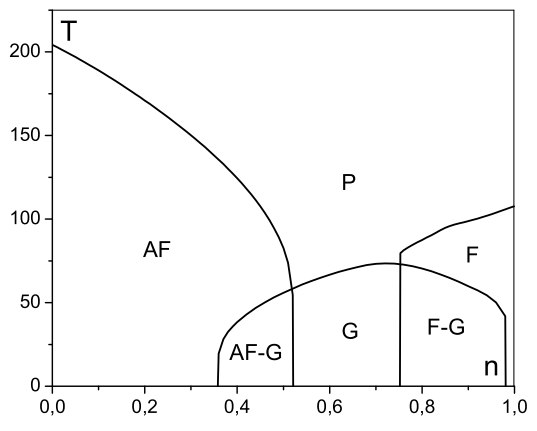

Figure 1. Phase diagram of RADA built for the model Hamiltonian parameters; $V_{f}=70 \mathrm{~K}$, $V_{a f}=-80 \mathrm{~K}, U_{f}=-40 \mathrm{~K}, U_{a f}=120 \mathrm{~K}, V=65 \mathrm{~K}, U=-210 \mathrm{~K}$.

The comparison of the obtained phase diagram with the ones presented in $[2,3]$ and with the experimental ones $[7,12]$ shows a better coincidence of curves in figure 1 with the experiment for RADA than the corresponding curves in $[2,3]$. However, there is some quantitative discrepancy in the critical points of concentration where the ferroelectric phases appear. Namely, this theoretical critical value is equal to $0.76-0.80$ whereas the experimental one is only $0.82-0.90$. At the same time the theoretical and experimental points of the occurrence of concentration for antiferroelectric phase are practically the same $(0.50-0.52)$. It must be noted that the theoretical and experimental critical concentrations completely coincide for deuterated material DRADA. The second fact which should be noted is a somewhat larger (about 20-25\%) calculated temperature of dipole glass compared to the experimental one. However, in our opinion, this difference in the calculated and in the observed values is not of great importance.

We should like to underline a sharply asymmetric behaviour of a phase diagram in figure 1, caused not only by the difference in the phase transition temperatures for pure crystals (for RDA $T_{\mathrm{c}}=110 \mathrm{~K}$ and for ADA $T_{N}=216 \mathrm{~K}$ ) but also, in our observations, due to the mixed system evidently tending to antiferroelectric type of ordering instead of the ferroelectric one at corresponding (small or large $n$ ) regions of concentration. As a result, the percolation phenomena for both these phases take place at nonsymmetric points. 


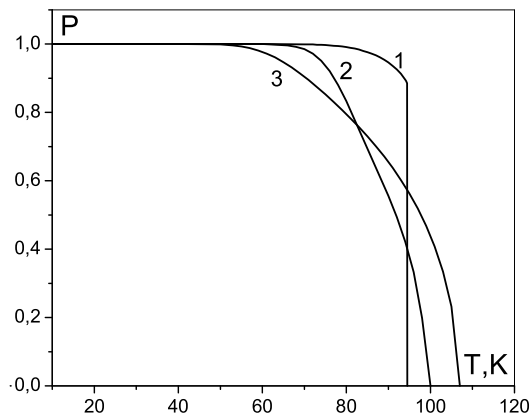

Figure 2. Ferroelectric order parameters: versus temperature for some fixed concentrations; curves: $1-n=0.80,2-n=0.90,3-n=0.99$. The model Hamiltonian parameters are the same as in figure 1 .

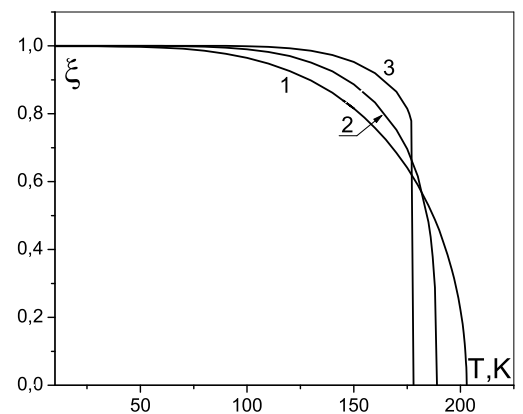

Figure 3. Antiferroelectric order parameters versus temperature for some fixed concentrations; curves: $1-n=0.01,2-n=0.10$, $3-n=0.30$. The model Hamiltonian parameters are the same as in figure 1.

The temperature dependencies of ferroelectric $(P)$ and antiferroelectric $(\xi)$ order parameters at certain fixed concentrations are presented in figure 2 and figure 3 . It is natural that the temperature of corresponding phase transitions (turning $P$ or $\xi$ into zero) decreases when the relative concentration of ferroelectrically or antiferroelectrically ordering particles becomes lower. But one can also observe the changes in critical behaviour of order parameters under concentration. For both types of ordering those changes show a constant tendency: order parameters behave more smoothly when the corresponding concentration increases. So, we constantly observe the second order phase transitions for pure crystals and the second order phase transition close to the first order one in a frustration region of concentration. It is interesting to note that short range interparticle interactions are similar to the effect of a partial omission of interacting sites of a crystal. In a deluted crystal the role of short range forces is more important compared to the long range ones.

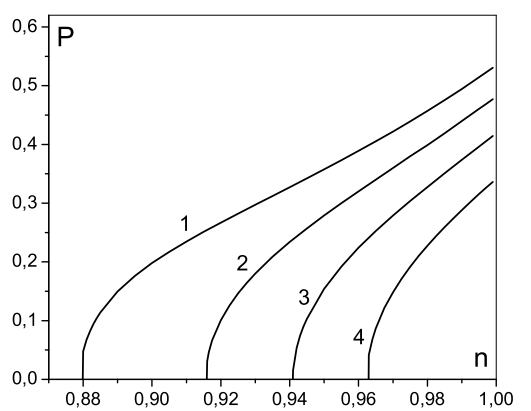

Figure 4. Ferroelectric order parameters versus concentration for some fixed temperatures; curves: $1-T=98 \mathrm{~K}, 2-T=100 \mathrm{~K}$, $3-T=102 \mathrm{~K}, 4-T=104 \mathrm{~K}$. The model Hamiltonian parameters are the same as in figure 1.

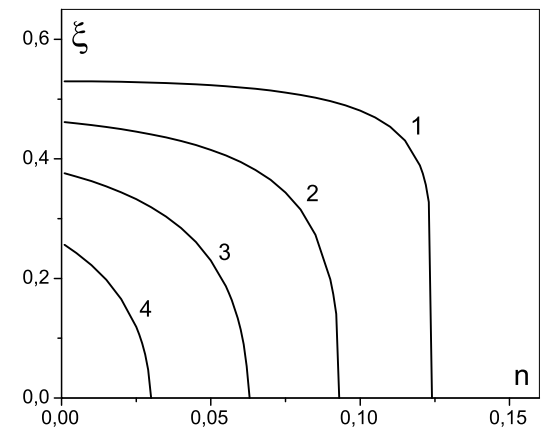

Figure 5. Antiferroelectric order parameters versus concentration for some fixed temperatures; curves: $1-T=185 \mathrm{~K}, 2-T=190 \mathrm{~K}$, $3-T=195 \mathrm{~K}, 4-T=200 \mathrm{~K}$. The model Hamiltonian parameters are the same as in figure 1.

The concentration behaviours of both order parameters are presented in figure 4 and figure 5 . Those curves are built at fixed temperatures for which the corresponding ordered phases exist. 
The temperature and concentration behaviours of other thermodynamic functions of the system investigated are strictly dependent on the behaviour of $P$ and $\xi$.

\title{
References
}

1. Korynevskii N.A., J. Conf. Abs., 2003, 8, 192.

2. Korynevskii N.A., Baran O.R., Ferroelectrics, 2004, 300, 151.

3. Korynevskii N.A., Solovyan V.B., Ferroelectrics, 2005, 317, 19.

4. Trybula Z., Stankowski J., Blinc R., Ferroelectric Lett., 1986, 6, 57.

5. Kim S., Kwun S., Phys. Rev. B, 1990, 42, 638.

6. Trybula Z., Schmidt V., Drumheller J., Phys. Rev. B, 1991, 43, 1287.

7. Trybula Z., Stankowski J., Condens. Matter Phys., 1998, 1, 311.

8. Lanceros-Mendes S., Schmidt V., Shapiro S., Ferroelectrics, 2004, 300, 117.

9. Edwards S.F., Anderson P.W., J. Phys. E, 1975, 5, 965.

10. Bidaux R., Carton J.P., Sarma G., J. Phys. A: Math. Gen., 1976, 9, L87.

11. Yukhnovskii I.R., Korynevskii N.A., Phys. Stat. Sol. (b), 1989, 153, 583.

12. Trybula Z., Kaszynski J., Maluszynska H., Ferroelectrics, 2005, 316, 125.

\section{Сегнето-акнтисегнетоелектричні змішані системи. Рівняння стану, термодинамічні функції}

\author{
М.А.Кориневський ${ }^{1,2}$, В.Б.Солов'ян ${ }^{1}$ \\ 1 Інститут фізики конденсованих систем НАН України, \\ 179011 Львів, вул. Свєнціцького, 1 \\ 2 Інститут фізики Щецінського університету, \\ Польща, 70451 щецін, вул. Велькопольська, 15 \\ Отримано 19 серпня 2005 р.
}

Обговорюється проблема рівняння стану сегнето- антисегнетоелектричної змішаної системи в діапазоні повної зміни концентрації $(0 \leqslant n \leqslant 1)$. Головною особливістю моделі, що розглядається, $€$ можливості сегнетоелектричного впорядкування вузлових дипольних моментів в напрямку осі $z$, або ж ї антисегнетоелектричного впорядкування - в напрямку осі $x$. Аналогічна ситуація має місце у змішаних сполуках типу KDP. Виявлено і проаналізовано умови існування різноманітних фаз (сегнето-, антисегнето-, параелектричної, дипольного скла та деяких їх змішаних комбінацій).

Ключові слова: сегнетоелектрики і антисегнетоелектрики, змішані системи, рівняння стану

PACS: $75.10 . H k, 77.22 . C h, 77.84 . F$ 
